\title{
An 11-digit identification system for individual Nile crocodiles using natural markings
}

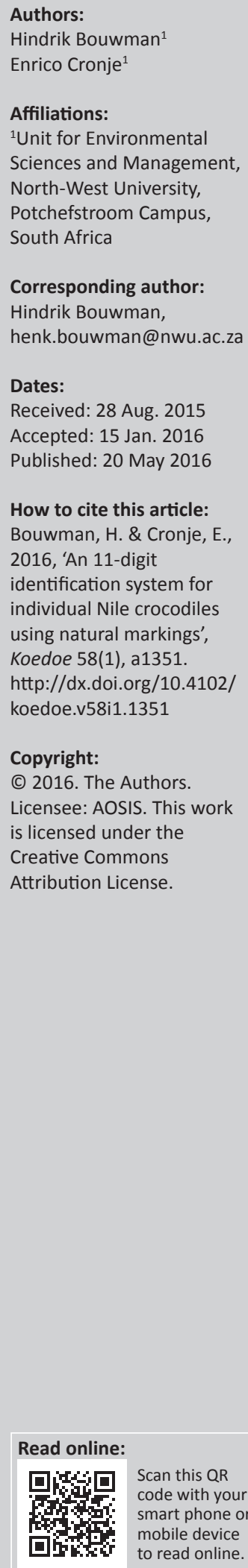

Research and conservation of wild crocodiles and husbandry of captive crocodiles requires the reliable identification of individuals. We present a method using the individual colour markings on the first 10 single-crest scutes on the tails of Nile crocodiles (Crocodylus niloticus). The scutes are scored by number for colour, with a prefix for left or right providing a binary 11-digit identification number (identification numbers [IDs]; e.g. 12232232242 and 22333233232) per crocodile. A survey of 359 captive Nile crocodiles showed no duplication. However, $42 \%$ had asymmetrical scute markings requiring a binary approach. There does not seem to be a change in patterns with age, except that the number of missing scutes increased. A small trial showed that this method can be applied in the field, although more work is needed to determine observer bias and establish parameters for observability in the field. It is unlikely that both left and right IDs would be obtainable for each individual, but other distinctive markings such as scute shape and damage can be used to register the two IDs to one individual. Having two independent IDs for each crocodile provides the possibility of two independent population estimates for equal effort without having to link left and right IDs to individuals. Our proposed method would be useful in conservation, individual tracking and husbandry.

Conservation implications: A non-invasive marking and recapture method for Nile crocodile is presented whereby the first 10 single-crest scutes are scored for colour, allowing conservation practitioners to count and monitor crocodile populations and individuals. This method provides two equal-effort estimations of population size, as left and right hand sides are scored independently.

\section{Introduction}

The reasons for accurate counts of crocodiles in any system can vary, but most likely mainly involves research and conservation. An impetus to count Nile crocodiles (Crocodylus niloticus) in the Kruger National Park (KNP) occurred during the 2008/2009 mortality episodes in the Olifants, Letaba and Sabie rivers. The numbers of animals that died remain uncertain but at least 170 carcasses were found (Ferreira \& Pienaar 2011), with smaller numbers of carcasses in subsequent years. Near the confluence of the Olifants and Letaba rivers and downstream into the Olifants River Gorge, crocodile numbers (using various counting techniques) declined from 780 in 2008 to 505 in 2009. Elsewhere in southern Africa, crocodile numbers have also declined in Loskop Dam (Oberholster et al. 2010) and Flag Boshielo Dam (Dabrowski, Oberholster \& Dabrowski 2014), Ndumu Game Reserve (Calverly \& Downs 2014), Lake Sibaya (Combrink et al. 2011), and the panhandle of the Okavango Delta (Bourquin \& Leslie 2011), or remained constant or increased slightly in the Gonarezhou National Park (Zisadza-Gandiwa et al. 2013) and some rivers in the KNP (Ferreira \& Pienaar 2011).

There are a number of constraints with deriving crocodile population estimates. The fraction of the actual number of crocodiles that are available for sampling is the detectability bias. The detectability bias is dependent on many factors, including time of day (or night), season, vantage point (height, aerial platform, flat terrain, etc.), proportion of animals under water and not detected, and size and age of the crocodile, etc. (Ferreira \& Pienaar 2011; Calverley \& Downs 2014; Zisadza-Gandiwa et al. 2013 and their references). Fixed-wing and helicopter counts consistently yielded lower estimates than night-time spotlight surveys (Ferreira \& Pienaar 2011; Combrink et al. 2011). However, correction factors or estimates can be applied to any counting technique to derive population estimates (Ferreira \& Pienaar 2011; Combrink et al. 2011; Calverley \& Downs 2014; Bayliss et al. 1986).

Estimating populations can also be done using mark-recapture (e.g. Bayliss et al. 1986; Nair et al. 2012). The constraints here are dependent largely on equal catchability of the crocodiles in the 
system and marking a large enough proportion of the crocodiles. This did not prove feasible in the Olifants River Gorge area in the KNP, using plastic tags attached to tail scutes and/or scute clipping (Ferreira \& Pienaar 2011). However, a similar method was used successfully in the panhandle of the Okavango Delta, where 224 of 1717 marked individuals were recaptured over 4 years (Bourquin \& Leslie 2011). However, capturing and marking individuals is time-consuming, may alter the behaviour of the individuals (Bourquin \& Leslie 2011; Underhill \& Fraser 1989), there could be marker loss, and there may be catchability and re-catchability bias in size or age classes and sex (Bayliss et al. 1986), amongst a number of factors.

Several of these factors can be reduced when using natural markings on the animal, not least of which are avoiding the direct and lingering effects of capture and handling, and the relative permanency of the marks. Crocodile surveys using natural mark schemes have been used successfully (Swanepoel 1996; Nair et al. 2012). Both used variations of the method developed by Singh \& Bustard (1976). These methods use unique marking (dark blotches) on the sides of the tail and the single crest of scutes on the tail. However, none of these have tested the possibility of duplication between animals, comparisons between left and right aspects and the scoring system employed does not easily lend itself to computer comparisons. We describe and test a binary 11-digit, identification system for individuals based on the colour and presence or absence of the first 10 proximal scutes of the single crest.

\section{Methods}

From proximal to distal on the dorsal posterior of the Nile crocodile, there is a double-row or crest of scutes that changes to a single row where the tail narrows. Each of these scutes has a colour pattern or is absent because of injury. We visited a crocodile farm to compile a photographic database of as many crocodiles as possible. Using a high-definition camera, photographs were taken of the tail sections of the 10 proximal single-crest scutes of Nile crocodiles of various age groups, ranging from a few months to over 20 years of age (Figures 1a and $1 \mathrm{~b}$ ). Each of the single-crest scutes has a colour pattern consisting of white or light to dark or black, or absent. The first 10 single-crest scutes were scored proximal to distal.

Initially, we assumed that the scute colouration would be symmetrical, that is, the left and right sides of the scutes would be identical, therefore enabling the identification number (ID) to be the same regardless of which side the crocodile is viewed from. However, this was not the case (see results). This means that to accurately identify a crocodile, the researcher must be able to view both sides of the tail. If only the right side of a crocodile's tail has been recorded in the past and the left side of that same crocodile's tail is now recorded without being able to see the right side, the database might register it as a new crocodile whilst the crocodile has already been recorded, leading to inaccurate population estimates. The scoring system accommodates this by allocating the first digit to orientation. It is therefore possible over time to complete a database for a certain area with both the left and right sides of all the crocodiles recorded, as certain crocodiles are scored again when both sides of the tail are visible.

The first digit of the 11-digit ID donates the aspect of the tail that is scored; left (1), right (2), or uncertain or unknown (3). Scoring of the 10 scutes is done by assigning a number to each scute based on the particular colouration:

- $\quad$ First digit - Left $=1$, right $=2$, unknown $=3$.

- A missing or damaged scute $=0$.

- A white or light scute $=1$.

- A scute less than $50 \%$ dark or black $=2$.

- A scute more than $50 \%$ dark or black $=3$.

- A completely dark or black scute $=4$.

- A scute that cannot be scored $=5$.

Each crocodile therefore, has two, linked, 11-digit ID numbers with 9765625 possible unique ID numbers per side, excluding the missing scute category. We assigned IDs to 359 Nile crocodiles of the Castlekop Crocodile Farm near Barberton, Mpumalanga. The IDs were entered into a Microsoft Excel 2007 database and scanned for duplicates. As mentioned above, we also tested for asymmetry. Except for frequencies (Table 1; Figure 2), further statistics including reporting of means is not possible as the data per colour score are categorical and not normally distributed because of many zeros in some colour categories.

We trialled this method in the field to see if Nile crocodile scutes can be scored with binoculars and super-zoom cameras. We also scanned our photograph collections for scorable photos to see if opportunistic 'tourist' photographs may be useful.

\section{Results}

At Castlekop, we scored 49 Nile crocodile individuals in the 0 - to 1-year age group, 140 in the 1-7-year age group, 159 in the 7-20-year age group and 11 in the group older than 20 years. These categories were dictated by the housing of the crocodiles in age-pens. Figures $1 \mathrm{a}$ and $1 \mathrm{~b}$ show the left and right views of the same juvenile crocodile (0-1 year) with respective IDs of 12232232242 and 22333233232, which is asymmetrical. Of 56 crocodiles that were photographed from both sides, $62 \%$ of the left or right scute colouration patterns were asymmetrical.

Figures 1c and 1d scored 13233233223 and 23222322332 for Nile crocodiles photographed in the wild in Botswana. Both have missing tails tips, but both have 10 scorable scutes. The scoring of the last scute of Figure 1c was difficult as it was in the shade, but could be done by zooming in. Figure 1e, a 'tourist' photo from the KNP (18× optical zoom), scored as 24212323433 after zooming in. Figure 1f (a tourist photo from Botswana with 20x zoom) scored 11221022142. Zooming in allowed the finding of the first single-crest scute that is not 

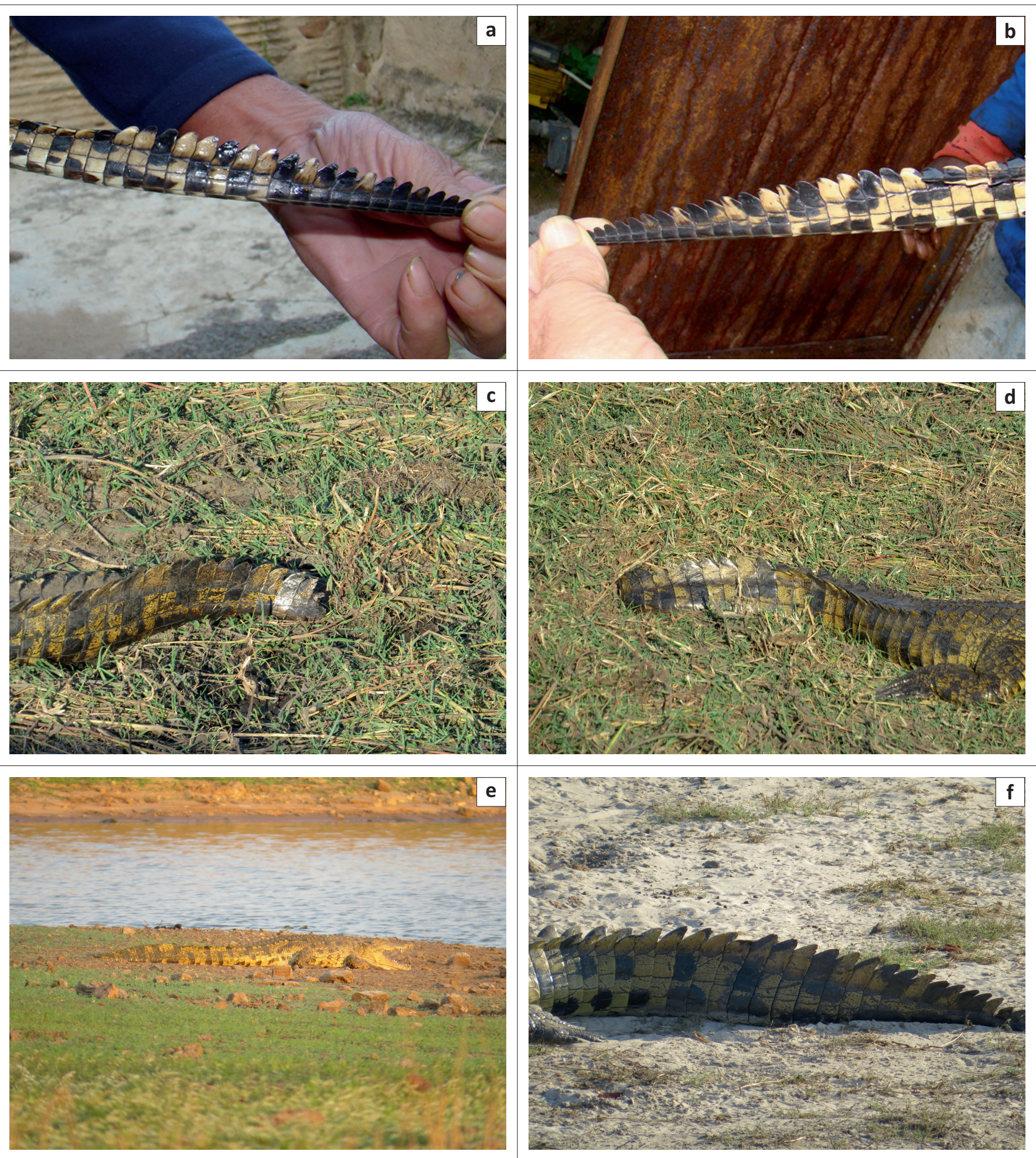

Source: Photographs ( $\mathrm{a}$ and b) taken by E. Conje; ( $\mathrm{c}$ and d) taken by H. Bouwman; (e) taken by P.J. Bouwman and (f) taken by B. Bouwman

FIGURE 1: Scute colouration as used for deriving identification numbers. (a and b) Left and right views of the same juvenile crocodile from Castlekop Crocodile Farm. Respective IDs are 12232232242 and 22333233232. (c and d) Views of two different crocodiles photographed in Botswana, with respective IDs of 13233233223 and 23222322332. (e and f) 'Tourist' photographs, taken in South Africa (24212323433 with 18x optical zoom) and Botswana (11221022142 with 20× optical zoom).

TABLE 1: Data of scores per age group from the Castlekop Crocodile Farm.

\begin{tabular}{|c|c|c|c|c|c|c|}
\hline Age & Number crocodiles & Light or white & $<50 \%$ Dark & $>50 \%$ Dark & Dark or black & Missing \\
\hline$\overline{0-1}$ & 49 & $14.9 / 65.3 / 7$ & $46.7 / 100 / 8$ & $26.7 / 97.9 / 7$ & $10.0 / 55.1 / 3$ & $3.1 / 22.4 / 4$ \\
\hline $1-7$ & 140 & $14.1 / 45.7 / 7$ & $36.4 / 96.2 / 7$ & $34.5 / 99.4 / 7$ & $11.1 / 67.9 / 4$ & $4.0 / 23.6 / 6$ \\
\hline $7-20$ & 159 & $17.6 / 74.2 / 7$ & $39.6 / 99.4 / 7$ & $27.2 / 94.9 / 8$ & $10.5 / 59.7 / 5$ & $5.0 / 31.4 / 6$ \\
\hline $20+$ & 11 & 28.1/90.9/7 & $30.9 / 90.9 / 5$ & $15.5 / 90.9 / 7$ & $9.1 / 63.3 / 3$ & $15.5 / 72.7 / 7$ \\
\hline
\end{tabular}

The first number in each colour column is the percentage of the total number of scutes with that colour category in that age group. The second number is the percentage of crocodiles with at least one scute in that colour category. The third number is the maximum number of scutes with that colour in any crocodile in that age group. 

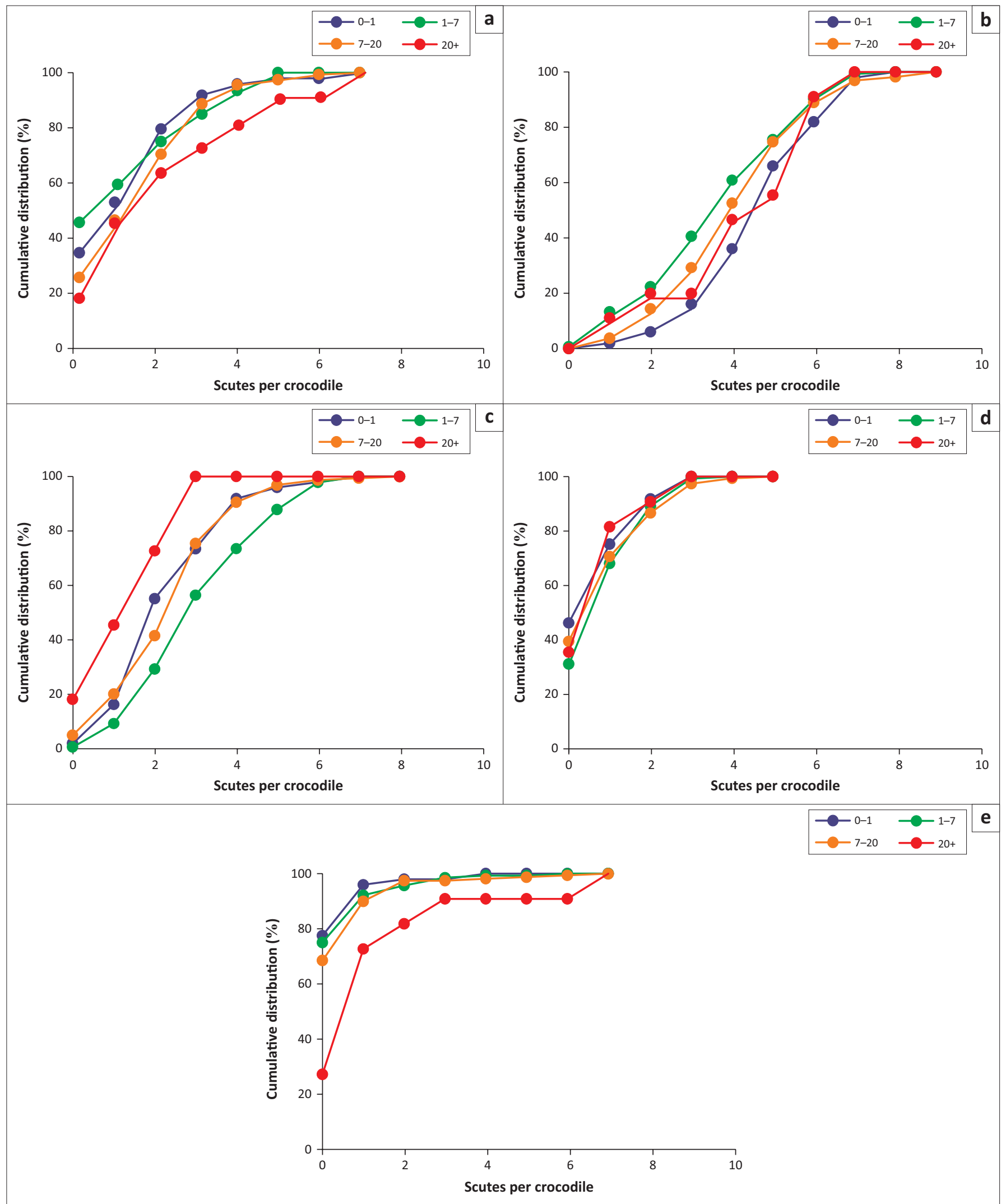

Source: Authors' own creation

FIGURE 2: Cumulative distribution of scute colouration per crocodile age group. (a) Cumulative distribution of light/white-coloured scutes per crocodile age group.

(b) Cumulative distribution of scutes that are less than $50 \%$ dark/black per age group. (c) Cumulative distribution of scutes that are more than $50 \%$ dark/black per age group. (d) Cumulative distribution of scutes that are completely dark/black per age group. (e) Cumulative distribution of missing scutes per age group. 
immediately apparent from the print. The sixth scute is partially missing (0). This characteristic could be used in registering the right ID with the left when this crocodile is sighted later from the other side.

Most of the Nile crocodile scutes scored in the $<50 \%$ or $>50 \%$ categories (Table 1), followed by light or white, dark or black and missing scutes. No consistent pattern of change in colour categories with age is apparent. With most of the scutes in the $>50 \%$ and $<50 \%$ categories, small differences in the light or white and dark or black categories will result in relatively large variable percentages between age groups. The consistent maximum number of scutes in any crocodile (third number in the columns) remained remarkably constant with age, except for missing scutes. Here, as can be expected, the percentages increased with age. The number of crocodiles with at least one missing scute increased from $22.4 \%$ in the youngest group to $72.7 \%$ in the oldest.

The cumulative distribution of the number of scutes per crocodile per colour score showed no crocodiles with all 10 scutes exclusively in one colour category (Figure 2). No crocodile had more than five dark or black scutes and none more than seven light or white scutes. Especially for the light or white (Figure 2a) and dark or black (Figure 2d) categories, up to $45 \%$ of the animals had none of either. None or almost none had no scutes with $<50 \%$ dark colouration (Figure 2b). Missing scutes (scored as 0) is likely to increase with age because of handling injury and fighting. This is apparent in Table 1 and in Figure 2. A small study on the banks of the Crocodile River (KNP) showed that 48 Nile crocodiles were repeatedly identified everyday over a period of a week.

\section{Discussion}

The chance of two Nile crocodiles in a population of 500 having the same ID is less than $0.0001 \%$, assuming that the colouration patterns are expressed randomly. Because it can be assumed that a reasonable proportion of the crocodiles that were photographed at the crocodile farm must be related, our findings show that there were no duplicates in ID numbers in a relatively isolated interbreeding group. In $48 \%$ of cases, the patterns were symmetrical, meaning that it cannot be presumed that a left and right ID would coincide. Because it is unlikely that both sides of the tail would be observable in the field, left and right IDs cannot be directly linked. There may be cases though, where scute wear patterns and/or missing scutes would be visible from both sides, as in Figure $2 \mathrm{f}$, where the sixth scute is partially missing. Visual comparisons of photographs would eventually register left and right IDs with a reasonable measure of confidence.

Having two ID numbers per crocodile is not ideal. However, for population studies, separate left and right ID numbers (even if linkable to registered individuals) would provide two independent estimations, probably providing more confidence in upper and lower population limits.
Table 1 and Figure 2 imply that, with the exception of missing scutes, colouration patterns and therefore ID numbers would remain relatively stable with age. This observation would need substantiation, probably best done in a captive population of Nile crocodiles, where a substantial number of individuals can be followed over a long period. For shortterm studies though, such as individual movement tracking and population estimates, stability of the IDs would most likely be sufficient. ID numbers that would change with age because of damage or missing scutes would not present an insurmountable problem, as identification through partial IDs in many circumstances may still be possible. In many cases, not all 10 scutes will be visible. Often, the last portion of the tail would still be in the water, curved away from the observer, or covered in mud. Here, identification using a partial ID score would in some cases still be possible if the scorable scutes, coupled with other distinctive markings such as scute shapes, have a unique combination.

Although this method was trailed successfully on a small scale on Nile crocodiles, the utility needs to be shown by larger and longer term studies. It will also be necessary to investigate observer bias in scoring crocodile scutes and to determine the parameters whereby identifications can be made with confidence, such as distance between the observer and crocodiles, approachability in the wild, light conditions and magnification needed for cameras and telescopes. However, sighting and re-sighting issues remain, likely biased against smaller individuals. Other limitations would be scutes covered in mud or algae. Assigning and recognising IDs could also be trailed using HD photographs taken from aerial platforms, or even using infrared optics at night. 'Tourist' photos might also prove useful in tracking individuals over time, especially if the cameras have geolocation built in. This method may also be applicable to other crocodilian species where the tails have distinctive and stable colour patterns.

This method may therefore prove useful in conservation (e.g. population estimates) and research (e.g. tracking of movements) that may also involve citizen participation, or keeping track of the ages, sex and conditions of individuals in the wild and captivity.

\section{Acknowledgements}

We thank Danie Pienaar and Xander Combrink, and Suria Ellis for help with some of the statistics. We also thank the Castlekop Crocodile Farm near Barberton, South Africa, in particular Charles Ferreira. Funding was provided by the National Research Foundation of South Africa. Opinions expressed and conclusions arrived at are those of the authors and are not necessarily to be attributed to the National Research Foundation (NRF).

\section{Competing interests}

The authors declare that they have no financial or personal relationships which may have inappropriately influenced them in writing this article. 


\section{Authors' contributions}

E.C. and H.B. conceived and planned the project. E.C. performed all the fieldwork. E.C. and H.B. analysed the data and prepared the manuscript.

\section{References}

Bayliss, P., Webb, G.J.W., Whitehead, P.J., Dempsey, K. \& Smith, A., 1986, 'Estimation of the abundance of saltwater crocodiles, Crocodylus porosus Schneider, in tida wetlands of the Northern Territory: A mark-recapture experiment to correct spotlight counts to absolute numbers, and the calibration of helicopter and spotlight counts', Australian Wildlife Research 13, 309-320.

Bourquin, S.L. \& Leslie, A.J., 2011, 'Estimating demographics of the Nile crocodile (Crocodylus niloticus Laurenti) in the panhandle region of the Okavango Delta, Botswana', African Journal of Ecology 50, 1-8.

Calverley, P.M. \& Downs, C.T., 2014, 'Population status of Nile crocodiles in Ndumu Game Reserve, KwaZulu-Natal, South Africa (1971-2012)', Herpetologia 70, 417-425.

Combrink, X., Korrübel, J.J., Kyle, R., Taylor, R. \& Ross, P., 2011, 'Evidence of a declining Nile crocodile (Crocodylus niloticus) population at Lake Sibaya, South Africa', South African Journal of Wildlife Research 41, 145-157.
Dabrowski, J., Oberholster, P.J. \& Dabrowski, J.M., 2014, 'Water quality of Flag Boshielo Dam, Olifants River, South Africa: Historical trends and the impact of drought', Water SA 40, 345-357.

Ferreira, S.M. \& Pienaar, D., 2011, 'Degradation of the crocodile population in the Olifants River Gorge of Kruger National Park', Aquatic Conservation: Marine and Freshwater Ecosystems 21, 155-164.

Nair, T., Thorbjarnarson, J.B., Aust, P. \& Krishnaswamy, J., 2012, 'Rigorous gharia population estimation in the Chambal: Implications for conservation and management of a globally threatened crocodilian', Journal of Applied Ecology 49, 1046-1054

Oberholster, P.J., Myburgh, J.G., Ashton, P.J. \& Botha, A.-M., 2010, 'Responses of phytoplankton upon exposure to a mixture of acid mine drainage and high levels of nutrient pollution in Lake Loskop, South Africa', Ecotoxicology and Environmental Safety 73, 326-335.

Singh, L.A.K. \& Bustard, H.R., 1976, 'A method to identify individual young gharial (Gavialis gangeticus)', British Journal of Herpetology 5, 669-671.

Swanepoel, D.G.J., 1996, 'Identification of the Nile crocodile Crocodylus niloticus by the use of natural tail marks', Koedoe 39, 113.

Underhill, L.G. \& Fraser, M.W., 1989, 'Bayesian estimate of the number of sunbirds feeding at an isolated and transient nectar resource', Journal of Field Ornithology 60, 382-387.

Zisadza-Gandiwa, P., Gandiwa, E., Jakarasi, J., van der Westhuizen, H. \& Muvengwi, J., 2013 'Abundance, distribution and population trends of Nile crocodile (Crocodylus niloticus) in Gonarezhou National Park, Zimbabwe', Water SA 39, 165-169. 